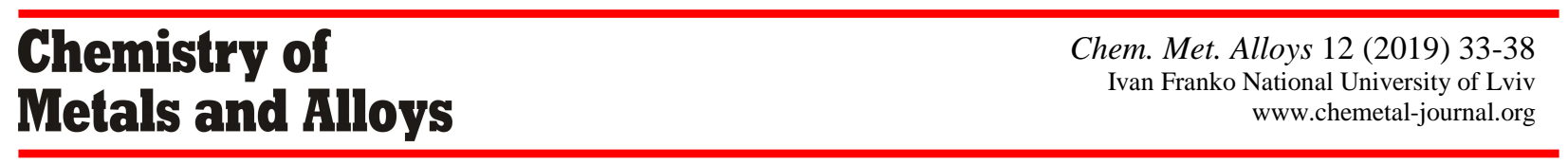

\title{
Crystal structure of the ternary compound $\mathrm{Gd}_{2} \mathrm{Ge}_{3.84} \mathrm{Sn}_{0.92}$
}

\author{
Roman DANKEVYCH ${ }^{1}$, Yaroslav TOKAYCHUK ${ }^{1 *}$, Roman GLADYSHEVSKII $^{1}$ \\ ${ }^{1}$ Department of Inorganic Chemistry, Ivan Franko National University of Lviv, \\ Kyryla i Mefodiya St. 6, 79005 Lviv, Ukraine \\ * Corresponding author.Tel.: +380-32-2394506; e-mail: tokaychuk@mail.lviv.ua
}

Received May 12, 2019; accepted June 18, 2019; available on-line January 1, 2020 https://doi.org/10.30970/cma12.0392

The new ternary intermetallic compound $\mathrm{Gd}_{2} \mathrm{Ge}_{3.84(4)} \mathrm{Sn}_{0.92(4)}$ was synthesized and its crystal structure was determined by X-ray powder diffraction (structure type $\mathrm{Nd}_{2} \mathrm{Ge}_{3.55} \mathbf{S n}_{1.24}$, Pearson symbol $o S 40$, space group Cmcm, $a=4.0434(6), b=35.284(6), c=4.1724(6) \AA, Z=4)$. The structure type $\mathrm{Nd}_{2} \mathrm{Ge}_{3.55} \mathrm{Sn}_{1.24}$ contains triple slabs of trigonal prisms stacked as in $\alpha-\mathrm{ThSi}_{2}$ and double square-mesh atom nets. It is a member of the linear intergrowth structure series built up from segments of the structure types $\mathrm{AlB}_{2}, \mathrm{CaF}_{2}$ and $\alpha$-Po. The zigzag chains of Ge atoms inside the central prism slab are deficient and the disordered atom arrangement is modeled by two split sites.

\section{Gadolinium / Germanium / Tin / X-ray powder diffraction / Crystal structure}

\section{Introduction}

The phase diagram of the ternary system $\mathrm{Gd}-\mathrm{Ge}-\mathrm{Sn}$ has to our knowledge not yet been investigated. The existence and crystal structures of two ternary compounds have been reported [1]: $\mathrm{GdGe}_{0.83} \mathrm{Sn}_{1.17}$ (ternary $\mathrm{ZrSi}_{2}$ type $\mathrm{ScCo}_{0.25} \mathrm{Si}_{1.75}, o S 12, \quad \mathrm{Cmcm}$, $a=4.3005, \quad b=16.441, \quad c=4.0944 \AA$ ) $\quad$ [2] and $\mathrm{Gd}\left[\mathrm{Ge}_{1-x} \mathrm{Sn}_{x}\right]_{2}$ (refined $\mathrm{Gd}_{2} \mathrm{Ge}_{2.930(28)} \mathrm{Sn}_{0.809(14)}$, own structure type, Pearson symbol $o S 32$, space group Cmcm, $a=4.2248, \quad b=30.451, \quad c=4.0013 \AA$ ) [3]. In a more recent work we reported the homogeneity range of the ternary $\mathrm{ZrSi}_{2}$-type phase at $600^{\circ} \mathrm{C}$ $\left(\mathrm{GdGe}_{0.75-1} \mathrm{Sn}_{1.25-1}, \quad a=4.3206(4), \quad b=16.4824(15)\right.$, $c=4.1270$ (4) $\AA$ for $\mathrm{GdGe}_{0.75} \mathrm{Sn}_{1.25}$ ) and the formation of a solid solution of substitution type $\mathrm{GdGe}_{0-0.15} \mathrm{Sn}_{2-1.85}$ $\left(0-5\right.$ at.\% Ge) based on the binary compound $\mathrm{GdSn}_{2}$ (type $\mathrm{ZrSi}_{2}, o S 12, C m c m, a=4.4023(6), b=16.399(3)$, $c=4.2795(6) \AA$ for $\mathrm{GdGe}_{0.15} \mathrm{Sn}_{1.85}$ ) [4]. The two $\mathrm{ZrSi}_{2}$-type phases are in equilibrium at $600^{\circ} \mathrm{C}$. Ternary $\mathrm{ScCo}_{0.25} \mathrm{Si}_{1.75}$-type compounds have also been observed in other ternary systems $R-\mathrm{Ge}-\mathrm{Sn}(R=\mathrm{Y}, \mathrm{Tb}, \mathrm{Dy}$, Ho, Er) [2], whereas only one compound, isotypic with $\mathrm{Gd}_{2} \mathrm{Ge}_{2.94} \mathrm{Sn}_{0.82}$ has been reported $\left(\mathrm{Tb}_{2} \mathrm{Ge}_{2.94} \mathrm{Sn}_{0.80}\right)$ [3]. In the same work the crystal structures of two other ternary compounds, $\mathrm{Nd}_{2} \mathrm{Ge}_{3.55} \mathrm{Sn}_{1.24}$ and $\mathrm{Sm}_{2} \mathrm{Ge}_{3.55} \mathrm{Sn}_{1.24}$ (structure type $\mathrm{Nd}_{2} \mathrm{Ge}_{3.55} \mathrm{Sn}_{1.24}, o S 40, \mathrm{Cmcm}$ ), were also reported.

The aim of the present work was to refine the crystal structure of the new ternary compound $\mathrm{Gd}_{2} \mathrm{Ge}_{3.84} \mathrm{Sn}_{0.92}$, which was found during an investigation of the phase equilibria in the ternary system $\mathrm{Gd}-\mathrm{Ge}-\mathrm{Sn}$ at $600^{\circ} \mathrm{C}$.

\section{Experimental}

An alloy of nominal composition $\mathrm{Gd}_{29} \mathrm{Ge}_{53} \mathrm{Sn}_{18}$ was synthesized from high-purity metals ( $\mathrm{Gd} \geq 99.9$ mass \%, $\quad \mathrm{Ge} \geq 99.999$ mass \%, $\mathrm{Sn} \geq 99.9$ mass \%) by arc melting in a water-cooled copper crucible under a purified argon atmosphere, using a tungsten electrode. To achieve high efficiency of the interaction between the components the sample was melted twice. After the synthesis the alloy was wrapped into tantalum foil, sealed in a quartz ampoule under vacuum and annealed at $600^{\circ} \mathrm{C}$ for $720 \mathrm{~h}$. Finally the ampoule with the sample was quenched into cold water. The weight loss did not exceed $1 \%$ of the total mass, which was approximately $1 \mathrm{~g}$.

An X-ray powder diffraction pattern was obtained at room temperature on a diffractometer STOE Stadi $\mathrm{P}$ with a linear position-sensitive detector $\left(\mathrm{Cu} K \alpha_{1}\right.$-radiation, angular range $6^{\circ} \leq 2 \theta \leq 110^{\circ}$, step $\left.0.015^{\circ}\right)$. The phase analysis of the sample, which was carried out using the WinXPOW program package [5], revealed the presence of three phases: a new ternary compound, $\mathrm{Gd}_{2} \mathrm{Ge}_{2.94} \mathrm{Sn}_{0.82}$, and tin. The positions and intensities of the diffraction peaks of the new compound and the similarity of the experimental $\mathrm{X}$-ray powder diffraction pattern with the X-ray pattern calculated for $\mathrm{Nd}_{2} \mathrm{Ge}_{3.55} \mathrm{Sn}_{1.24}$ [3] indicated possible formation of the structure type $\mathrm{Nd}_{2} \mathrm{Ge}_{3.55} \mathrm{Sn}_{1.24}$.

The crystal structure was refined by the Rietveld method using the FullProf Suite program package [6], starting from the atom coordinates of the structure type $\mathrm{Nd}_{2} \mathrm{Ge}_{3.55} \mathrm{Sn}_{1.24}$ [3]. 
The admixture phases, $\mathrm{Gd}_{2} \mathrm{Ge}_{2.94} \mathrm{Sn}_{0.82}$ and $\mathrm{Sn}$ (5.0(2) and 4.9(2) mass \%, respectively), were modeled with individual scale factors and cell parameters, while the profile parameters were constrained to be the same for all phases. For the main phase the following parameters were refined: a scale factor, three cell parameters, six profile parameters (pseudo-Voigt profile), ten positional, six displacement, four occupational parameters and one texture parameter. In total 37 parameters were included in the final cycles of the refinement. The background was defined using the Fourier filtering technique. Experimental, calculated and difference X-ray powder diffraction patterns are presented in Fig. 1; experimental details and crystallographic data for the individual phases in the alloy $\mathrm{Gd}_{29} \mathrm{Ge}_{53} \mathrm{Sn}_{18}$ are listed in Table 1 .

The composition of the new ternary compound was confirmed by local X-ray spectral analysis performed on a raster electron microscope REMMA-102-02 equipped with an energy dispersion X-ray spectrometer EDAR: $\mathrm{Gd}_{2.0(2)} \mathrm{Ge}_{3.9(2)} \mathrm{Sn}_{1.0(2)}$. A photograph of the polished surface of the sample of nominal composition $\mathrm{Gd}_{29} \mathrm{Ge}_{53} \mathrm{Sn}_{18}$ in a secondary electrons is shown in the inset of Fig. 1.

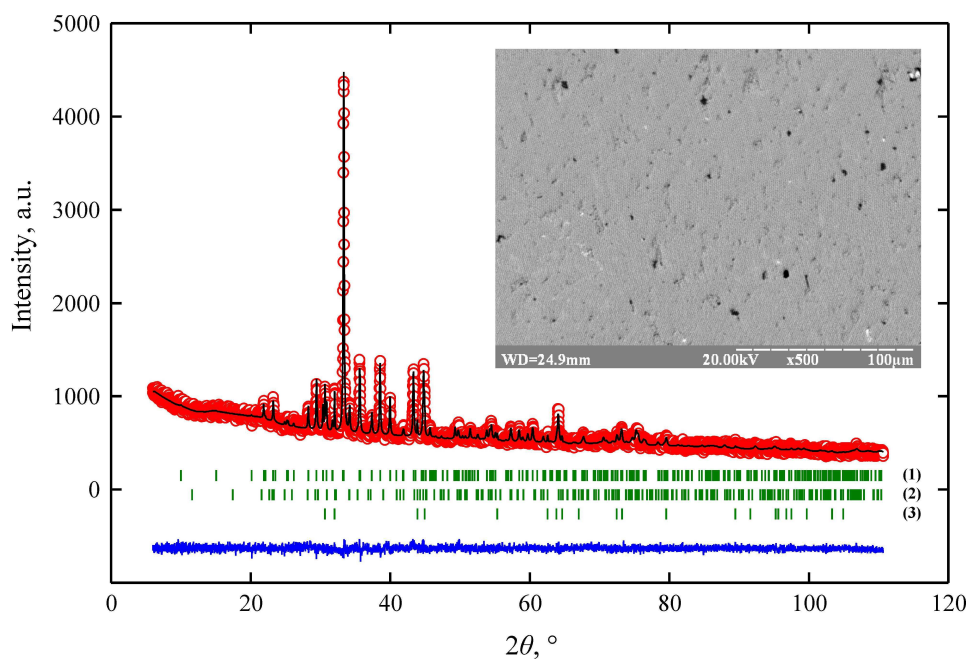

Fig. 1 Experimental (circles), calculated (continuous line) and difference between experimental and calculated (bottom) X-ray powder diffraction patterns of the sample $\mathrm{Gd}_{29} \mathrm{Ge}_{53} \mathrm{Sn}_{18}\left(\mathrm{Cu} K \alpha_{1}\right.$-radiation). Vertical bars indicate the positions of the reflections from $\mathrm{Gd}_{2} \mathrm{Ge}_{3.84} \mathrm{Sn}_{0.92}$ (1), $\mathrm{Gd}_{2} \mathrm{Ge}_{2.94} \mathrm{Sn}_{0.82}$ (2), and $\mathrm{Sn}$ (3). The inset shows a photograph of the polished surface of the sample in a secondary electrons.

Table 1 Experimental details and crystallographic data for the individual phases in the sample $\mathrm{Gd}_{29} \mathrm{Ge}_{53} \mathrm{Sn}_{18}$.

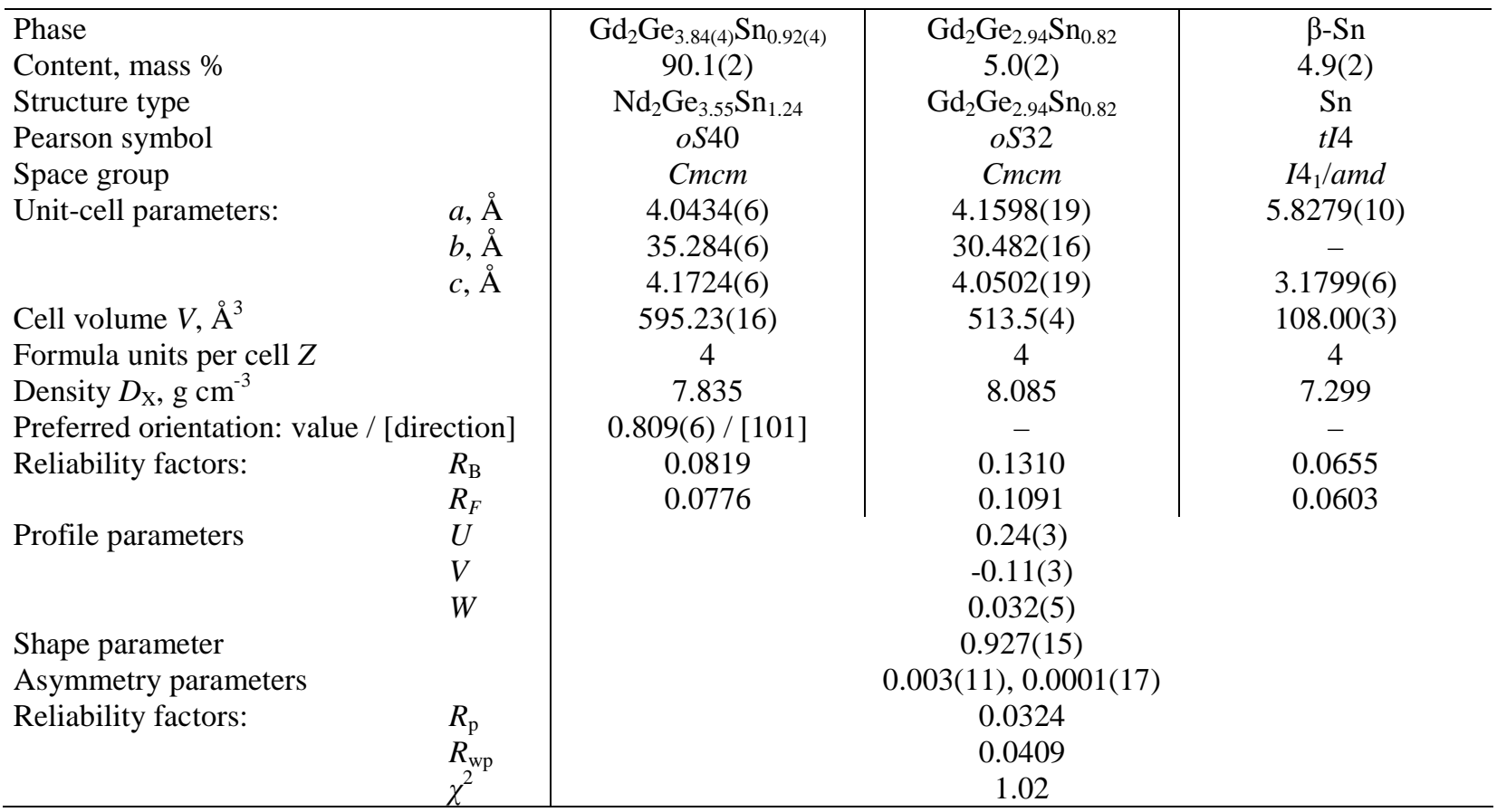




\section{Results and discussion}

The crystal structure of the ternary compound $\mathrm{Gd}_{2} \mathrm{Ge}_{3.84} \mathrm{Sn}_{0.92}$ belongs to the orthorhombic structure type $\mathrm{Nd}_{2} \mathrm{Ge}_{3.55} \mathrm{Sn}_{1.24}$. The atom coordinates and isotropic displacement parameters from the Rietveld refinement of $\mathrm{Gd}_{2} \mathrm{Ge}_{3.84(4)} \mathrm{Sn}_{0.92(4)}$ are given in Table 2. The structure is characterized by two sites occupied by $\mathrm{Gd}$ atoms, four sites by $\mathrm{Ge}$ atoms, and two sites by statistical mixtures of $\mathrm{Ge}$ and $\mathrm{Sn}$ atoms (Fig. 2). One of the main features of the structure is local positional disorder, which was modeled by considering two split positions in Wyckoff position $8 f$, occupied by 10 and $28 \%$ Ge, respectively, which approximately replace one 4-fold Ge site. The refined distances between neighboring positions of the split sites are: $1.25(15) \AA$ for the Ge 1 site and $0.55(10) \AA$ for the $\mathrm{Ge} 2$ site. It should be noted that the total occupancy of the Ge1 and Ge2 sites cannot exceed 0.5 , moreover, neighboring positions of these sites cannot be occupied simultaneously.

Table 2 Atomic coordinates, site occupancies and isotropic displacement parameters for $\mathrm{Gd}_{2} \mathrm{Ge}_{3.84(4)} \mathrm{Sn}_{0.92(4)}$

$\left(\mathrm{Nd}_{2} \mathrm{Ge}_{3.55} \mathrm{Sn}_{1.24}, o S 40, C m c m, a=4.0434(6), b=35.284(6), c=4.1724(6) \AA\right)$.

\begin{tabular}{c|c|c|c|c|c}
\hline Site & $\begin{array}{c}\text { Wyckoff } \\
\text { position }\end{array}$ & $x$ & $y$ & $z$ & $B_{\text {iso, }} \AA^{2}$ \\
\hline Gd1 & $4 c$ & 0 & $0.4485(5)$ & $1 / 4$ & $0.7(2)$ \\
Gd2 & $4 c$ & 0 & $0.8553(2)$ & $1 / 4$ & $0.8(2)$ \\
Ge1 (Occ. $=0.10(2))$ & $8 f$ & 0 & $0.012(4)$ & $0.100(8)$ & $1.4(-)$ \\
Ge2 (Occ. =0.28(2)) & $8 f$ & 0 & $0.0093(12)$ & $0.184(8)$ & $1.4(-)$ \\
Ge3 & $4 c$ & 0 & $0.0754(4)$ & $1 / 4$ & $1.4(3)$ \\
Ge4 & $4 c$ & 0 & $0.6230(4)$ & $1 / 4$ & $1.4(3)$ \\
$M 1(0.39(4) G e+0.61(4) \mathrm{Sn})$ & $4 c$ & 0 & $0.2130(3)$ & $1 / 4$ & $1.1(3)$ \\
$M 2(0.69(4) \mathrm{Ge}+0.31(4) \mathrm{Sn})$ & $4 c$ & 0 & $0.2874(4)$ & $1 / 4$ & $1.1(3)$ \\
\hline
\end{tabular}

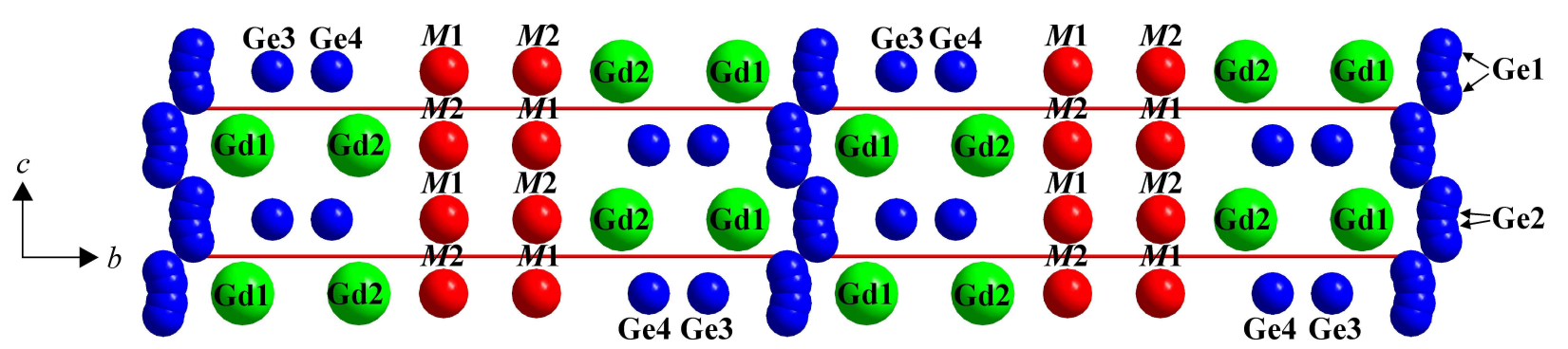

Fig. 2 Projection of the unit cell of the structure of $\mathrm{Gd}_{2} \mathrm{Ge}_{3.84} \mathrm{Sn}_{0.92}$ on the $b c$ plane.

Interatomic distances, coordination numbers and coordination polyhedra for the atoms in the structure of $\mathrm{Gd}_{2} \mathrm{Ge}_{3.84} \mathrm{Sn}_{0.92}$ are listed in Table. 3. The polyhedra

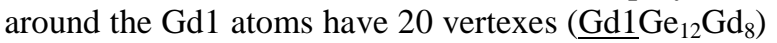
and can be described as pentagonal prisms $\mathrm{Ge}_{10}$ capped by two $\mathrm{Ge}$ and eight $\mathrm{Gd}$ atoms. The $\mathrm{Gd} 2$ atoms center square antiprisms $\mathrm{Ge}_{4} M_{4}$ with eight additional atoms, six $\mathrm{Gd}$ and two $\mathrm{Ge}$, forming 16-vertex polyhedra $\underline{\mathrm{Gd} 2} \mathrm{Ge}_{6} M_{4} \mathrm{Gd}_{6}$. The coordination polyhedra of the $\mathrm{Ge}$ atoms are trigonal prisms $\mathrm{Gd}_{6}$ with two $(\mathrm{Ge} 4)$ or three $(\mathrm{Ge} 1, \mathrm{Ge} 2$, and $\mathrm{Ge} 3$ ) additional $\mathrm{Ge}$ atoms above the rectangular faces. The closest coordination environments of the statistical mixtures of $\mathrm{Ge}$ and $\mathrm{Sn}$ atoms (M1 and $M 2)$ also have the shape of trigonal prisms, but are formed by $\mathrm{Gd}$ and $p$-element atoms $\left(M_{4} \mathrm{Gd}_{2}\right)$, with one additional atom centering a rectangular face. The polyhedra around sites $\mathrm{Ge} 1, \mathrm{Ge} 2, \mathrm{Gd} 1$, and Ge3 are deformed due to the positional disorder of the Ge atoms described by the splitting of the Ge1 and Ge2 sites.

The structure types $\mathrm{ZrSi}_{2}, \quad \mathrm{ScCo}_{0.25} \mathrm{Si}_{1.75}$, $\mathrm{Gd}_{2} \mathrm{Ge}_{2.94} \mathrm{Sn}_{0.82}$, and $\mathrm{Nd}_{2} \mathrm{Ge}_{3.55} \mathrm{Sn}_{1.24}$, which are adopted by the ternary phases in the system $\mathrm{Gd}-\mathrm{Ge}-\mathrm{Sn}$ at $600^{\circ} \mathrm{C}$ (solid solution $\mathrm{GdGe}_{0-0.15} \mathrm{Sn}_{2-1.85}$, ternary compounds $\mathrm{GdGe}_{0.75-1} \mathrm{Sn}_{1.25-1}, \mathrm{Gd}_{2} \mathrm{Ge}_{2.94} \mathrm{Sn}_{0.82}$, and $\mathrm{Gd}_{2} \mathrm{Ge}_{3.84} \mathrm{Sn}_{0.92}$ ), are closely related. The structure type $\mathrm{ScCo}_{0.25} \mathrm{Si}_{1.75}$ is a ternary variant of $\mathrm{ZrSi}_{2}$ with preferential substitution of $\mathrm{Co}$ for $\mathrm{Si}$ on one site, the same symmetry and similar unit-cell parameters. $\mathrm{GdGeSn}$ is expected to form an almost perfectly ordered structure. In all four structure types with pseudo-tetragonal unit cells similar structural fragments stacked along the crystallographic direction [010] can be considered: layers of trigonal prisms and planar square-mesh nets of atoms (Fig. 3). In the 
structure of the binary compound $\mathrm{GdSn}_{2}$ the trigonal prisms are centered by $\mathrm{Sn}$ atoms and the square nets are also formed by $\mathrm{Sn}$ atoms. In the partially ordered structure of the ternary compound GdGeSn the trigonal prisms are occupied mainly by Ge atoms, whereas the square nets are still formed by Sn atoms. In both structures these fragments alternate along the stacking direction, so that the structure can be considered to be an intergrowth of $\mathrm{AlB}_{2^{-}}$and $\mathrm{CaF}_{2}$-type segments. In the structures of $\mathrm{Gd}_{2} \mathrm{Ge}_{2.94} \mathrm{Sn}_{0.82}$ and $\mathrm{Gd}_{2} \mathrm{Ge}_{3.84} \mathrm{Sn}_{0.92}$ every second interlayer between prism slabs is occupied by a disordered arrangement of $\mathrm{Ge}$ atoms from split sites forming zigzag chains along the crystallographic direction [001] in $\mathrm{Gd}_{2} \mathrm{Ge}_{2.94} \mathrm{Sn}_{0.82}$ and [100] in
$\mathrm{Gd}_{2} \mathrm{Ge}_{3.84} \mathrm{Sn}_{0.92}$. These atoms also have trigonalprismatic coordination, however, the different directions of the above mentioned zigzag chains correspond to different stackings of the trigonal prisms: in the structure of $\mathrm{Gd}_{2} \mathrm{Ge}_{2.94} \mathrm{Sn}_{0.82}$ three consecutive layers of prisms are stacked through rectangular faces as in the structure type $\mathrm{AlB}_{2}$, whereas in the structure of $\mathrm{Gd}_{2} \mathrm{Ge}_{3.84} \mathrm{Sn}_{0.92}$ similar layers are rotated by $90^{\circ}$ as in the structure type $\alpha-\mathrm{ThSi}_{2}$. The planar square nets in the structure of $\mathrm{Gd}_{2} \mathrm{Ge}_{2.94} \mathrm{Sn}_{0.82}$ are in the structure of $\mathrm{Gd}_{2} \mathrm{Ge}_{3.84} \mathrm{Sn}_{0.92}$ replaced by two consecutive square layers, which form slabs of empty cubes. In both structures the square layers are formed by statistical mixtures of $\mathrm{Ge}$ and $\mathrm{Sn}$ atoms.

Table 3 Interatomic distances $(\delta)$ and coordination numbers $(\mathrm{CN})$ in the structure of $\mathrm{Gd}_{2} \mathrm{Ge}_{3.84(4)} \mathrm{Sn}_{0.92(4)}$ $\left(\mathrm{Nd}_{2} \mathrm{Ge}_{3.55} \mathrm{Sn}_{1.24}, o S 40, C m c m, a=4.0434(6), b=35.284(6), c=4.1724(6) \AA\right)$.

\begin{tabular}{|c|c|c|c|c|}
\hline & Atoms & $\delta, \AA$ & $\mathrm{CN}$ & Polyhedra \\
\hline Gd1 & $\begin{array}{l}-2 \mathrm{Ge} 2(2 \mathrm{Ge} 1) \\
-4 \mathrm{Ge} 2(4 \mathrm{Ge} 1) \\
-4 \mathrm{Ge} 3 \\
-2 \mathrm{Ge} 4 \\
-2 \mathrm{Gd} 2 \\
-2 \mathrm{Gd} 1 \\
-2 \mathrm{Gd} 1 \\
-2 \mathrm{Gd} 1\end{array}$ & $\begin{array}{c}2.96(3)(3.08(10)) \\
3.10(2), 3.45(2)(2.86(7)(3.66(5)) \\
3.025(4) \\
3.274(12) \\
3.860(9) \\
4.0434(6) \\
4.1724(6) \\
4.190(9)\end{array}$ & 20 & $\underline{\mathrm{Gd} 1} \mathrm{Ge}_{12} \mathrm{Gd}_{8}$ \\
\hline $\mathrm{Gd} 2$ & $\begin{array}{l}-4 \mathrm{Ge} 4 \\
-2 M 2 \\
-2 M 1 \\
-2 \mathrm{Ge} 3 \\
-2 \mathrm{Gd} 1 \\
-2 \mathrm{Gd} 2 \\
-2 \mathrm{Gd} 2\end{array}$ & $\begin{array}{l}3.004(4) \\
3.135(12) \\
3.187(10) \\
3.214(12) \\
3.860(9) \\
4.0434(6) \\
4.1724(6) \\
\end{array}$ & 16 & $\underline{\mathrm{Gd}} 2 \mathrm{Ge}_{6} M_{4} \mathrm{Gd}_{6}$ \\
\hline $\mathrm{Ge} 1$ & $\begin{array}{l}-2 \mathrm{Ge} 1 \\
-1 \mathrm{Ge} 3 \\
-2 \mathrm{Gd} 1 \\
-4 \mathrm{Gd} 1\end{array}$ & $\begin{array}{c}2.25(8), 1.19(14), 3.44(5) \\
2.32(14) \\
2.96(3) \\
2.86(7), 3.66(5)\end{array}$ & 9 & $\underline{\mathrm{Ge} 1} \mathrm{Ge}_{3} \mathrm{Gd}_{6}$ \\
\hline $\mathrm{Ge} 2$ & $\begin{array}{l}-2 \mathrm{Ge} 2 \\
-1 \mathrm{Ge} 3 \\
-2 \mathrm{Gd} 1 \\
-4 \mathrm{Gd} 1\end{array}$ & $\begin{array}{c}2.187(18), 1.67(2), 2,714(14) \\
2.35(4) \\
3.08(10) \\
3.10(2), 3.45(2)\end{array}$ & 9 & $\underline{\mathrm{Ge}} 2 \mathrm{Ge}_{3} \mathrm{Gd}_{6}$ \\
\hline Ge3 & $\begin{array}{l}-1 \mathrm{Ge} 2(1 \mathrm{Ge} 1) \\
-2 \mathrm{Ge} 4 \\
-4 \mathrm{Gd} 1 \\
-2 \mathrm{Gd} 2\end{array}$ & $\begin{array}{c}2.35(4)(2.32(14)) \\
2.628(13) \\
3.025(4) \\
3.214(12) \\
\end{array}$ & 9 & $\underline{\mathrm{Ge}} 3 \mathrm{Ge}_{3} \mathrm{Gd}_{6}$ \\
\hline $\mathrm{Ge} 4$ & $\begin{array}{l}-2 \mathrm{Ge} 3 \\
-4 \mathrm{Gd} 2 \\
-2 \mathrm{Gd} 1 \\
\end{array}$ & $\begin{array}{l}2.628(13) \\
3.004(4) \\
3.274(12) \\
\end{array}$ & 8 & $\underline{\mathrm{Ge}} 4 \mathrm{Ge}_{2} \mathrm{Gd}_{6}$ \\
\hline$M 1$ & $\begin{array}{l}-1 M 2 \\
-4 M 2 \\
-2 \mathrm{Gd} 2 \\
\end{array}$ & $\begin{array}{l}2.625(18) \\
2.9051(3) \\
3.187(10) \\
\end{array}$ & 7 & $\underline{M 1} M_{5} \mathrm{Gd}_{2}$ \\
\hline$M 2$ & $\begin{array}{l}-1 M 1 \\
-4 M 1 \\
-2 \mathrm{Gd} 2 \\
\end{array}$ & $\begin{array}{l}2.625(18) \\
2.9051(3) \\
3.135(12)\end{array}$ & 7 & $\underline{M 2} M_{5} \mathrm{Gd}_{2}$ \\
\hline
\end{tabular}

$\overline{M 1}=0.39(4) \mathrm{Ge}+0.61(4) \mathrm{Sn} ; M 2=0.69(4) \mathrm{Ge}+0.31(4) \mathrm{Sn}$; italic font indicates alternative interatomic distances due to splitting of the sites Ge1 and Ge2 
The structure types $\mathrm{Gd}_{2} \mathrm{Ge}_{2.94} \mathrm{Sn}_{0.82}$ and $\mathrm{Nd}_{2} \mathrm{Ge}_{3.55} \mathrm{Sn}_{1.24}$ may be derived from the binary type TII $(o S 8, C m c m)$, represented in the system $\mathrm{Gd}-\mathrm{Ge}-\mathrm{Sn}$ by the germanide $\mathrm{GdGe}$ [7]. The structure type TII is characterized by the presence of zigzag chains of $\mathrm{Tl}$ atoms ( $\mathrm{Ge}$ atoms in $\mathrm{GdGe}$ ) centering trigonal prisms. By inserting a planar square-mesh atom net between the slabs of fused trigonal prisms the structure type $\mathrm{ZrSi}_{2}(o S 12, C m c m)$ [8] can be obtained, whereas on inserting two directly superposed planar square-mesh atom nets the structure type $\mathrm{DyGe}_{3}(o S 16, \quad$ Cmcm $)$ [9] is obtained. Adding layers of trigonal prisms (three stacked layers of prisms) to $\mathrm{ZrSi}_{2}$ and $\mathrm{DyGe}_{3}$, respectively, the structure types $\mathrm{Gd}_{2} \mathrm{Ge}_{2.94} \mathrm{Sn}_{0.82}$ and $\mathrm{Nd}_{2} \mathrm{Ge}_{3.55} \mathrm{Sn}_{1.24}$ can be obtained. Combination of the structure types $\mathrm{ZrSi}_{2}$ and $\mathrm{DyGe}_{3}$ leads to the formation of the structure type $\mathrm{Er}_{2} \mathrm{Ge}_{5}$ (oP14, Pmmm) [10], which can be considered as a stacking of three kinds of fragment: layers of trigonal prisms, single planar square-mesh atom nets and double square-mesh atom nets.
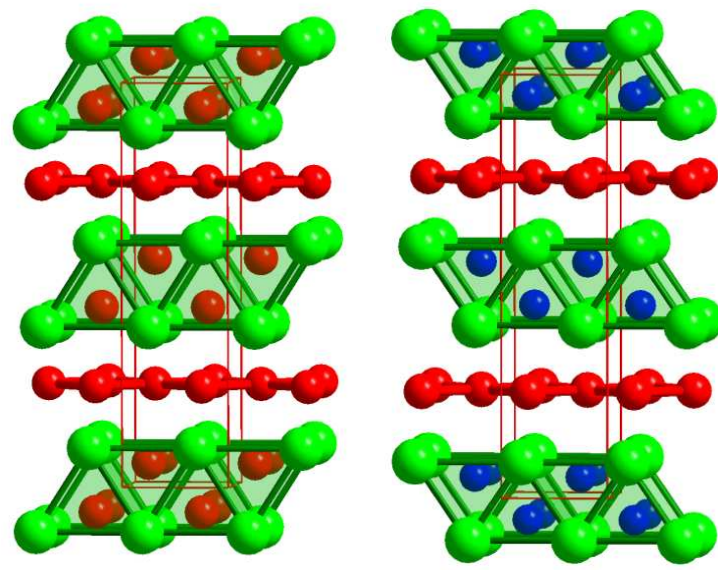

$\mathbf{G d S n}_{2}$
$\left(\mathrm{ZrSi}_{2}\right)$

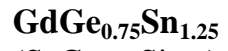

$\left(\mathrm{ScCo}_{0.25} \mathrm{Si}_{1.75}\right)$

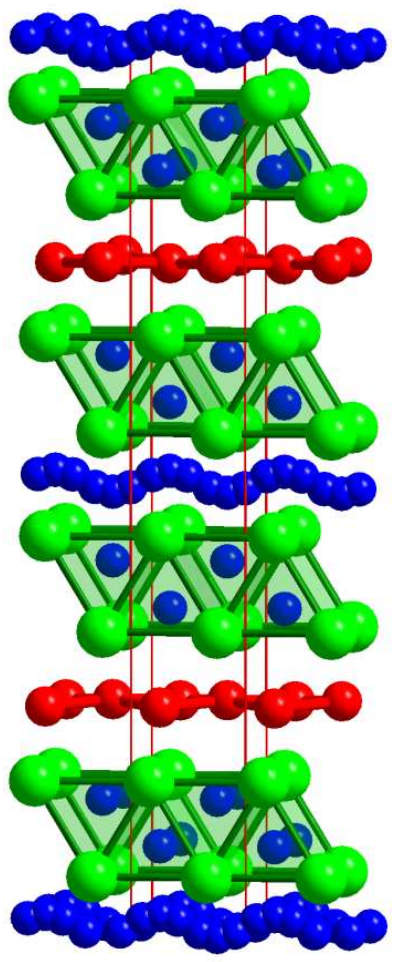

$\mathbf{G d}_{2} \mathbf{G e}_{2.94} \mathbf{S n}_{0.82}$ (own)

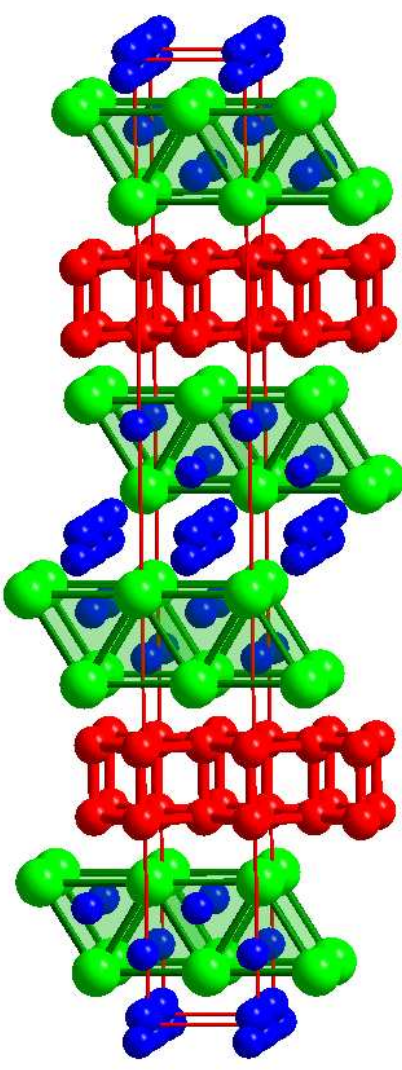

$\mathbf{G d}_{\mathbf{2}} \mathbf{G e}_{3.84} \mathbf{S n}_{\mathbf{0 . 9 2}}$ $\left(\mathrm{Nd}_{2} \mathrm{Ge}_{3,55} \mathrm{Sn}_{1,24}\right)$

Fig. 3 Stacking of trigonal prisms and planar square nets in the structures of $\mathrm{GdSn}_{2}, \mathrm{GdGe}_{0.75} \mathrm{Sn}_{1.25}$, $\mathrm{Gd}_{2} \mathrm{Ge}_{2.94} \mathrm{Sn}_{0,82}$, and $\mathrm{Gd}_{2} \mathrm{Ge}_{3.84} \mathrm{Sn}_{0.92}$ along the crystallographic direction [010] (green balls - Gd, red balls $\mathrm{Sn}$, blue balls - Ge atoms).

The structure types $\mathrm{Gd}_{2} \mathrm{Ge}_{2.94} \mathrm{Sn}_{0.82}$ and $\mathrm{Nd}_{2} \mathrm{Ge}_{3.55} \mathrm{Sn}_{1.24}$ are members of the family of orthorhombic structure types including also $\mathrm{TbGe}_{2}$ (oS24, Cmmm) [11], $\mathrm{PrGe}_{1.91}$ (oS36, Cmmm) [12], $\mathrm{DyGe}_{1.85}\left(o S 24, C m c 2_{1}\right)$ [13], and $\mathrm{YGe}_{1.82}$ (oS28, Cmcm) [14], which contain triple layers of trigonal prisms and square-mesh atom nets and represent a linear intergrowth of $\mathrm{AlB}_{2}$-type and $\mathrm{CaF}_{2}$-type slabs [15]. The structure types $\mathrm{Gd}_{2} \mathrm{Ge}_{2.94} \mathrm{Sn}_{0.82}$ and $\mathrm{YGe}_{1.82}$ are partly disordered derivatives of the DyGe $_{1.85}$ type with similar cell parameters and can be represented as a linear intergrowth of triple $\mathrm{AlB}_{2}$-type slabs, formed by trigonal prisms stacked as in $\mathrm{AlB}_{2}$ itself, but with different modeling of the disordered atom arrangement observed in the central prism layer, and single $\mathrm{CaF}_{2}$-type slabs. The structure type $\mathrm{Nd}_{2} \mathrm{Ge}_{3.55} \mathrm{Sn}_{1.24}$ can be derived from the $\mathrm{TbGe}_{2}$ and $\mathrm{PrGe}_{1.91}$ types, in which the layers of trigonal prisms are stacked as in the $\alpha-\mathrm{ThSi}_{2}$ type (mutually perpendicular prism axes in neighboring layers), but differs from these by the presence of Po-type slabs (two consecutive square-mesh atom nets $)-\left(\mathrm{AlB}_{2}{ }^{4}\left|\mathrm{AlB}_{2}{ }^{5}\right| \mathrm{AlB}_{2}{ }^{4}\left|\mathrm{CaF}_{2}{ }^{1}\right| \mathrm{Po}^{2} \mid \mathrm{CaF}_{2}{ }^{1}\right)_{2}$ according to the notation used in TYPIX [15], where the superscripts indicate local symmetry in the stacking sequence. 


\section{Conclusions}

The new ternary compound $\mathrm{Gd}_{2} \mathrm{Ge}_{3.84} \mathrm{Sn}_{0.92}$ was synthesized and its crystal structure was refined by the Rietveld method from X-ray powder diffraction data. The structure belongs to the structure type $\mathrm{Nd}_{2} \mathrm{Ge}_{3.55} \mathrm{Sn}_{1.24}$, which is closely related to the structure types $\mathrm{TbGe}_{2}, \mathrm{PrGe}_{1.91}, \mathrm{DyGe}_{1.85}, \mathrm{YGe}_{1.82}$, and $\mathrm{Gd}_{2} \mathrm{Ge}_{2.94} \mathrm{Sn}_{0.82}$. These structure types belong to homologous series of structures containing fragments of the structure types $\mathrm{AlB}_{2}$ and $\mathrm{CaF}_{2}$.

\section{Acknowledgement}

This work was carried out under the grant of the Ministry of Education and Science of Ukraine No. 0118 U003609.

\section{References}

[1] P. Villars, K. Cenzual (Eds.), Pearson's Crystal Data - Crystal Structure Database for Inorganic Compounds, ASM International, Materials Park, OH, USA, Release 2017/18.

[2] P.H. Tobash, J.J. Meyers, G. DiFilippo, S. Bobev, F. Ronning, J.D. Thompson, J.L. Sarrao, Chem. Mater. 20 (2008) 2151-2159.

[3] P.H. Tobash, S. Bobev, F. Ronning, J.D. Thompson, J.L. Sarrao, J. Alloys Compd. 488 (2009) 511-517.
[4] R. Dankevych, Ya. Tokaychuk, R. Gladyshevskii, Coll. Abstr. XIII Int. Conf. Cryst. Chem. Intermet. Compd., Lviv (2016) 97.

[5] WinXPow. Version 2.21, Stoe \& Cie GmbH, Darmstadt, 2007.

[6] J. Rodríguez-Carvajal, Commission on Powder Diffraction (IUCr), Newsletter 26 (2001) 12-19.

[7] N.C. Baenziger, J.L Moriarty. Jr., Acta Crystallogr. 14 (1961) 946-947.

[8] H. Schachner, H. Nowotny, H. Kudielka, Monatsh. Chem. 85 (1954) 1140-1153.

[9] P. Schobinger Papamantellos, D.B. De Mooij, K.H.J. Buschow, J. Alloys Compd. 183 (1992) 181-186.

[10] G. Venturini, I. Ijjaali, B. Malaman, J. Alloys Compd. 288 (1999) 183-187.

[11] P. Schobinger Papamantellos, D.B. De Mooij, K.H.J. Buschow, J. Less-Common Met. 144 (1988) 265-274.

[12] I. Savysyuk, N. Semuso, R. Gladyshevskii, Chem. Met. Alloys 10 (2017) 69-75.

[13] I.R. Mokra, V.K. Pecharskii, Z.M. Shpyrka, O.I. Bodak, V.K. Belskii, I.E. Patz, Dopov. Akad. Nauk Ukr. RSR, Ser. B 3 (1989) 45-47.

[14] I. Ijjaali, G. Venturini, B. Malaman, J. Alloys Compd. 284 (1999) 237-242.

[15] E. Parthé, L. Gelato, B. Chabot, M. Penzo, K. Cenzual, R. Gladyshevskii, TYPIX Standardized Data and Crystal Chemical Characterization of Inorganic Structure Types, Springer-Verlag, Berlin, 1993, Vols. 1-4, 1596 p. 